\title{
The Selling of Primary Care 2015
}

\author{
Walter N. Kernan, $M D^{7}$, D. Michael Elnicki, $M D^{2}$, and Karen E. Hauer, $M D^{3}$ \\ 'Department of Internal Medicine, Yale University School of Medicine, New Haven, CT, USA; ${ }^{2}$ Department of Medicine, University of Pittsburgh, \\ Pittsburgh, PA, USA; ${ }^{3}$ Department of Medicine, University of California San Francisco, San Francisco, CA, USA.
}

The role of undergraduate medical education in creating, perpetuating, and potentially solving the physician shortage in adult primary care has been debated for years, but often the discussions revolve around overly simplistic notions of supply and demand. The supply is curtailed, it is said, because the work is hard and the pay is low relative to other career options. Missing is a recognition that medical schools make choices in developing primary care learning environments that profoundly affect student perceptions of this career. Emerging developments in healthcare, including the transformation of academic health centers into integrated health systems that enter into risk-based contracts, may provide an opportunity to re-direct discussions about primary care. More schools may begin to recognize that they can control the quality of primary care teaching environments, and that doing so will help them achieve excellence in education and compete in the new marketplace. The selling of primary care to medical schools may be the first step in primary care selling itself to medical students.

J Gen Intern Med 30(9):1376-80

DOI: $10.1007 / \mathrm{s} 11606-015-3364-9$

(C) Society of General Internal Medicine 2015

"If you build it, he will come."

- Field of Dreams

\section{INTRODUCTION}

US medical schools are not graduating enough students who want to practice family medicine or general internal medicine, thus contributing to a manpower shortage in adult primary care. $^{2-6}$ Concerns about this shortage have grown in response to changes in health care financing, which are increasing the number of Americans with health insurance and encouraging the growth of new practice models, including accountable care organizations, that rely on primary care services. ${ }^{7,8}$ Growing numbers of patients with insurance and new models of care mean that academic health centers (AHCs) will be asked to train more primary care physicians.

Interpretations of the shortage in primary care physicians and its solutions have divided the medical profession. In one camp are those who believe that schools have little ability to influence career choice because they cannot counter the higher professional fees and greater work satisfaction that attract students to other fields. In the other are those who believe that

Published online July 15, 2015 schools can influence career choice by leading students to a more hopeful, forward-looking understanding of the specialty. ${ }^{9}$

Without denying the importance of economic context, in this Perspective we explain how medical schools may have contributed to the primary care shortage and the options they now have for helping to fix it. We call particular attention to student experiences in primary care practice. ${ }^{10}$

\section{The Role of Undergraduate Medical Education in the Primary Care Crisis}

Undergraduate medical education (UME) has played a complicated role in the shortfall of adult primary care physicians. Starting about 30 years ago, a push to move UME teaching into ambulatory care settings resulted in major restructuring of clerkship education. ${ }^{11}$ Internal medicine clerkships evolved from purely in-patient experiences to include roughly $30 \%$ time in clinic today. ${ }^{12,13}$ Coincidentally, educators developed improved methods for clinic-based instruction that emphasized 1:1 learner-centered teaching, meaningful student responsibility in patient care, and more supportive learning environments. ${ }^{12-18}$ Although office-based clerkships became popular among students, they were not enough to attract them to primary care specialties. ${ }^{9,19-21}$

In evaluating career options, students place high value on the potential for work satisfaction and a controllable lifestyle. ${ }^{19}$ Unfortunately, what they often find during rotations in primary care is not reassuring. ${ }^{20,22-24}$ This effect is more commonly discussed in the context of residency training where teaching clinics are often under-resourced and illsuited to manage the socially and medically complex patients served in these venues. ${ }^{25-29}$ Residents turn from careers in primary care when they experience the stress, disorganization, lack of continuity, lack of support, and low prestige in these settings, ${ }^{26,28-30}$ and students who observe these experiences may also opt away from primary care careers.

Student clerkships typically use more diverse office settings compared with residency programs, and the teaching environments are often better resourced and organized for more effective personalized care. ${ }^{28}$ However, physicians in these practices often work excessive hours and demonstrate lifestyles that students shun. Small practices, furthermore, are less likely to feature team-based care that students learn is necessary for optimal patient management and professional satisfaction. ${ }^{31,32}$ 
In both small and large practices, general internal medicine and family medicine are characterized by lower salaries compared with subspecialties, ${ }^{33}$ but also escalating requirements for documentation and increasing complexity of care. $^{34,35}$ The overall image for students is short visits with patients who need more, and physicians who struggle to keep up with their work. Compared to the hospital and subspecialty clinics, students see office-based primary care as less intellectual, invigorating, socially pleasant for professionals, and supported.

Clinical experience is just one factor contributing to an institutional culture or "hidden curriculum" that may attract or dissuade students from primary care. ${ }^{36,37} \mathrm{Cul}$ ture is heavily influenced by leadership, but perpetuated by mission statements, role models, and activities. Across the US, culture and experience converge so that students who matriculate with an interest in primary care tend to wander away during years of pre-doctoral training. ${ }^{38}$

\section{Commonly Discussed Solutions to the Adult Primary Care Physician Shortage}

Payment reform to reduce the income gap between primary care and other specialties, ${ }^{20,34,39-41}$ is beyond the control of any medical school. Other approaches to mitigate the primary care physician shortfall include making primary care delivery more efficient and increasing the number of medical school graduates who choose this field. Efficiency is important, but is too often measured with unit production metrics (i.e., number of patients seen/provider/day). Forcing physicians to see more patients in shorter visits degrades the work of primary care and enhances stress. More meaningful measures of efficiency consider access, patient satisfaction, and health outcomes. When these more meaningful measures are combined with team-based care and other workplace reforms, both efficiency and work satisfaction may improve. $^{42-51}$

Expansion of medical school capacity is already underway, ${ }^{52}$ but is not expected to produce the necessary growth in primary care physicians because student selection for primary care careers is falling or stable..$^{22,52-55}$ The Council on Graduate Medical Education recently estimated that the nation's needs will not be met until $40 \%$ of practicing physicians are in primary care ${ }^{5}$ - a percentage that cannot be achieved with the current $20 \%$ selection rate. Therefore, expansion of medical school capacity is not likely to address the shortfall in primary care physicians.

Student debt relief and admission management are two potential methods to increase the proportion of students who select primary care. Student debt may have a modest effect on career choice, but the effect is complex ${ }^{41,56,57}$ and other factors seem to be at least as important. ${ }^{10,20,37,41,58-62}$ Women, older students, and students from rural areas are more likely to choose primary care careers, ${ }^{10,36,57,63}$ but admission strategies selecting for these features have not been tested and there is some evidence to doubt they would succeed. ${ }^{58}$ Thus, debt relief and admission management are of modest or uncertain value in influencing career choice.

\section{An Educational Approach to Re-Making Pri- mary Care}

The culture and experiences in medical school that currently dissuade students from primary care hold the keys to reversing this effect. In particular, if students are placed in practices where work is intellectually challenging, professionally fulfilling, and compatible with a workable lifestyle, they will be drawn to it. Practices that display this more hopeful understanding of primary care feature efficient communication among team members, standardized work flows, rapid access for patients, continuity between patient and provider, patient-centered care, and team-based work in an environment staffed by highly effective professionals..$^{2,31,43,51}$ By analogy, a good clinic is like a superb physician role model who attracts students to his or her field. ${ }^{64,65}$

Many schools would not chose to develop effective primary care practices just to draw students into primary care careers, and they should not. There are more important reasons. Clinic environments have a large effect on how students understand and internalize an institution's humanistic values. They show how a school believes care should be organized, provided, and packaged. They show students how care should be delivered. Every school, therefore, should be concerned about putting students in excellent primary care environments because they are also concerned about teaching good medicine.

Building better primary care is also a necessary part of the evolution of an academic health center (AHC) toward an integrated enterprise that can succeed financially in the new, competitive, value-conscious healthcare market place. ${ }^{8,66,67}$ Primary care is a foundation for these new enterprises because of its role in population health for symptom evaluation, prevention, chronic disease management, and cost restraint. Strong partnerships between primary care and other specialties and subspecialties then supports high-quality care that is proactive, coordinated, and cost-efficient. A likely consequence of $\mathrm{AHC}$ modernization may be the elimination of separate clinics for resident education that selectively serve disadvantaged patients. Separate facilities may signify an institution's charitable intent, but they are rarely equal and often signify acceptance of variable quality and differing commitment to patients based on means. Modern AHCs often adopt corporate, uniform standards of quality that would likely prohibit two-tiered systems. 
Table 1 Eight Medical Schools Strategies to Foster Student Interest in Primary Care

1 Require clinical training in family medicine or primary care internal medicine. ${ }^{75-7}$

2 Place students in high-performance primary care sites. ${ }^{9,78}$

3 Create a school culture that values primary care.

a Adopt excellence and innovation in primary care as a school goal.

b In formal course work on health systems, teach about the foundational role of primary care

c Manage school-operated primary care clinics to be highperformance practices.

d Eliminate disparities in quality of care among sites sponsored by the school.

e Hire and promote faculty who develop and test innovative approaches to primary care practice, education, and policy.

$\mathrm{f}$ Offer primary care tracks for selected students $\mathrm{s}^{3,72,75} \cdot *$
$\mathrm{~g}$ Develop a model practice for innovation in team-based primary care.

h Support a successful department of family medicine. ${ }^{10}$

4 Create strategic educational alliances with local practices, organizations, and groups that have or seek to develop highperformance primary care services. ${ }^{68}$

5 Support primary care teaching faculty. $t$

6 Put student and resident education in primary care on an equal footing. Provide equal access to equally good clinical sites for students and residents.

7 Train students in systems-based analysis, including healthcare outcome, to foster understanding of the design and administration of effective primary care clinics.

8 Train students in population-based health care, an essential concept in emerging models of accountable care. ${ }^{66,79}$

* Special tracks are already offered or soon to be offered at several schools, including Duke, UC Davis, and Johns Hopkins

tExamples include Harvard Medical School and the University of Connecticut

$\ddagger$ Strategies include awarding RVUs for precepting students, lump sum payment per student per rotation, teacher training, and subsidies for continuing medical education

The idea of raising practice standards at teaching sites poses a quandary for schools that do not own enough primary care practices to meet the needs of their students. Most schools place some students in clinics owned by affiliated hospitals, local health care organizations, and private physicians. Some of these clinics are high-performing sites and perfectly suited to primary care training. Others may not be. If sufficient community-based practices are not available, the solution may be community engagement to support local practice innovation. ${ }^{68}$ As schools become or join accountable care organizations, they may be able to shift funds to support primary care.

Our suggestions for fostering student interest in primary care are summarized in the Table 1. Many relate to training students in high-functioning sites, but others include teaching about healthcare systems, offering select students a primary care track, and coordinating primary care training in all programs and at all levels of an institution. Schools with a family medicine department are more likely to graduate students who choose careers in primary care,${ }^{10}$ and it has been suggested that departments of internal medicine should cede the training of generalists to family medicine. ${ }^{69}$ A more viable pathway will lead these two disciplines to share their strengths and thereby raise the average quality of clinical training and research in each. ${ }^{70}$

\section{CONCLUSION}

Improving student experiences in primary care is not just necessary for re-building a primary care workforce. It is also necessary to assure that students internalize core professional values in patient-centered care and acquire an accurate understanding of modern health care delivery. However, the suggestion to place students selectively in high-performing clinics has been criticized as "bait and switch." in these sites, the criticism goes, will find they have been deceived when they land in the real world where work is more difficult and less satisfying. This criticism is without merit for several reasons. First, the purpose is not just to attract students to primary care - it is to teach students to respect patients and to prepare them to deliver high-quality care. Second, highfunctioning models of primary care that are adopted by medical schools may influence the standard as management practices are disseminated. Third, students who graduate will take with them expectations for collaborative, satisfying, patientcentered practice that will empower them to be agents of change. $^{72}$

Many educators who are willing to set aside the bait and switch argument may still object that they cannot afford improved primary care education. Low rates of reimbursement for primary care mean fewer resources for staffing, technology, and innovation required for the initiation of practice redesign and population-based care. We agree that insurers do not pay for schools to transform their practices. To expose students to excellent primary care practices, schools have two choices: they can raise capital to transform the practices they own or forge strategic alliances with practices that have already transformed. Schools know how to raise capital from internal revenue sharing, philanthropy, and endowment allocation, and some schools have begun to transform their primary care operations with these financial sources. ${ }^{8,73,74}$ The greater obstacle is making the decision to transform and tap into these resources. In the emerging health care system, improved systems for primary care should be expected to fund themselves. Better use of technology, improved allocation of human resources, ${ }^{2,51}$ and more effective disease prevention and treatment should reduce healthcare costs.

To encourage schools to develop improved primary care practice venues, our "pitch" would be, "You do not need to re-orient your mission or your curriculum to direct all students to primary care. However more students will choose this discipline if you redesign your primary care practice experience to show students what is possible and reflect your values for excellence in patient care. You don't need to actively attract students to primary care. Just avoid repelling them." Building excellence in primary care is certainly easier when the institutional culture values this field, but a supportive institutional culture is not necessary if deans, department 
chairs, and senior faculty agree that good, ethical patient care is the basis for good education.

Conflict of Interest: The authors declare that they do not have a conflict of interest.

Corresponding Author: Walter N. Kernan, MD; Department of Internal Medicine Yale University School of Medicine, Suite 515, 2 Church St. South, New Haven, CT 06519, USA (e-mail: Walter.Kernan@Yale.Edu).

\section{REFERENCES}

1. Robinson PA. Field of Dreams. Universal Pictures; 1989. p. 107 minutes.

2. Bodenheimer T, Pham HH. Primary care: current problems and proposed solutions. Health Aff. (Millwood). 2010;29:799-801.

3. Schwartz MD, Basco WT, Grey MR, Elmore JG, Rubenstein A. Rekindling student interest in generalist careers. Ann. Intern. Med. $2005 ; 142: 715-24$

4. Petterson SM, Liaw WR, Phillips RL, Rabin DL, Meyers DS, Bazemore AW. Projecting US primary care physician workforce needs: 2010-2025. Ann. Fam. Med. 2012;10:503-9.

5. Council on Graduate Medical Education. Twientieth Report: Advancing Primary Care. In: Services DoHaH, editor. Rockville2010.

6. Health Resources Services Administration. Physician Supply and Demand: Projections to 2020. Washington, DC: Health Resources and Services Administration; 2006.

7. Blumenthal D, Collins SR. Health care coverage under the affordable care act - a progress report. N. Engl. J. Med. 2014;371:275-81.

8. Berkowitz SA, Pahira JJ. Accountable care organization readiness and academic medical centers. Acad. Med. 2014;89:1210-5.

9. Fincher R-ME. The road less traveled-attracting students to primary care. N. Engl. J. Med. 2004;351:630-2.

10. Martini CJM, Veloski JJ, Barzansky B, Xu G, Fields SK. Medical school and student characteristics that influence choosing a generalist career. JAMA. 1994;272:661-8.

11. Perkoff GT. Teaching clinical medicine in the ambulatory setting. An idea whose time may have finally come. N. Engl. J. Med. 1986;314:27-31.

12. Shaheen A, Papp KK, Torre D. The internal medicine clerkship and ambulatory learning experiences: results of the 2010 Clerkship Directors in Internal Medicine Survey. Teach. Learn. Med. 2013;25:225-30.

13. Hemmer PA, Griffith C, Elnicki DM, Fagan M. The internal medicine clerkship in the clinical education of medical students. Am. J. Med. 2003; 115:423-7.

14. Irby DM. Teaching and learning in the ambulatory care settings: a thematic review of the literature. Acad. Med. 1995;70:898-931.

15. Lesky LG, Hershman WY. Practical approaches to a major educational challenge. Training students in the ambulatory setting. Arch. Intern. Med. 1995; 155:897-904

16. Irby DM, Ramsey PG, Gillmore GM, Schad D. Characteristics of effective teachers of ambulatory care medicine. Acad. Med. 1991;66:54-5.

17. Kernan WN, Lee MY, Stone SL, Freudigman KA, O'Connor PG. Effective teaching for preceptors of ambulatory care: a survey of medical students. Am. J. Med. 2000;108:499-502.

18. Neher JO, Gordon KC, Meyer B, Stevens N. A five-step "microskills" model of clinical teaching. J. Am. Board Fam. Pract. 1992;5:419-24.

19. Hauer KE, Durning SJ, Kernan WN, et al. Factors associated with medical students' career choices regarding internal medicine. JAMA 2008;300:1154-64.

20. Steinbrook R. Easing the shortage in adult primary care - is it all about the money? N. Engl. J. Med. 2009;360:2696-9.

21. Volpintesta EJ. How can we get students to chose primary are careers? Acad. Med. 2013;88:1789.

22. Schwartz MD, Durning S, Linzer M, Hauer KE. Changes in medical students' views of internal medicine careers 1990-2007. Arch. Intern. Med. 2011;171:744-9.

23. Smith RS. A recipe for medical schools to produce primary care physicians. N. Engl. J. Med. 2011;364:496-7.

24. Whitcomb ME, Cohen JJ. The future of primary care medicine. N. Engl. J. Med. 2004;351:710-2
25. Dowdy Dw. Trained to avoid primary care. Ann. Intern. Med. 2011;154:776-7.

26. Nadkarni M, Reddy S, Bates CK, Fosburgh B, Babbott S, Holmboe ES. Ambultory-based education in internal medicine: current organization and implications for transformatin. Results of a national survey of resident continuity clinic directors. J. Gen. Intern. Med. 2010;26:16-20.

27. Peccoralo LA, Tackett S, Ward L, et al. Resident satisfaction with continuity clinic and career choice in general internal medicine. J. Gen. Intern. Med. 2013;28:1020-7.

28. Keirns CC, Bosk CL. The unintended consequences of training residents in dysfunctional outpatient settings. Acad. Med. 2008;83:498-502.

29. Heist K, Guese M, Nikels M, Swigris R, Chacko K. Impact of $4+1$ block scheduling on patient care continuity in resident clinic. J. Gen. Intern. Med. 2014;29:1195-9.

30. Willett L. The paradoxical influence of resident continuity clinic on primary care. J. Grad. Med. Educ. 2012:552.

31. Margolius D. Less tinkering, more tranforming. How to build successful patient-centered medical homes. JAMA Intern. Med. 2013;173:1702-3.

32. Editor. Making primary care people-centered: a 21 st century blueprint. Lancet. 2014;384:281.

33. MGMA. Physician Compensation and Production Survey: 2014 Report based on 2013 data2014.

34. Bodenheimer T. Primary care - will it survive. N. Engl. J. Med. 2006;355:861-4.

35. Phillips RL. Primary care in the United States: problems and possiblities. Br. Med. J. (Clin. Res. Ed). 2005;331:1400-2.

36. Erikson CE, Danish S, Jones KC, Sandberg SF, Carle AC. The role of medical school culture in primary care careeer choice. Acad. Med. 2013;88:1919-26.

37. Bland CJ, Meurer LN, Maldonado G. Determinants of primary care specialty choice: a non-statistical meta-analysis of the literature. Acad. Med. 1995;70:620-41.

38. Babbott D, Baldwin DC, Jolly P, Williams DJ. The stability of early specialty preferences among US medical school graduates in 1983. JAMA. 1988;259: 1970-5.

39. Bodenheimer T, Berenson RA, Rudolf $\mathbf{P}$. The primary care-specialty income gap: why it matters. Ann. Intern. Med. 2007;146:301-6.

40. Bodenheimer T, Grumbach $\mathbf{K}$, Berenson RA. A lifeline for primary care. N. Engl. J. Med. 2009;360:2693-6.

41. Phillips RL, Dodoo MS, Petterson SM, et al. Specialty and Geographic Distribution of the Physician Workforce: What Influences Medical Student and Resident Choices? Washington, DC: The Robert Graham Center; 2009.

42. Baron RJ, Davis K. Accelerating the adoption of high-value primary care a new provider type under Medicare? N. Engl. J. Med. 2014;370:99-101.

43. Sinsky CA, Willard-Grace R, Schutzbank AM, Sinsky TA, Margolius D, Bodenheimer T. In search of joy in practice: a report of 23 highfunctioning primary care practices. Ann. Fam. Med. 2013;11:272-8.

44. Nelson KM, Helfrich C, Sun $\mathbf{H}$, et al. Implementation of the patientcentered medical home in the Veterans Health Administration. Associations with patient satisfaction, quality of care, staff burnout, and hospital and emergency department use. JAMA Intern. Med. 2014;174:1350-8.

45. Bodenheimer T. A lesson from the trenches-a high functioning primary care clinic. N. Engl. J. Med. 2011;635:5-8.

46. Grumbach $\mathbf{K}$. The patient-centered medical home is not a pill. Implications for evaluating primary care reforms. JAMA Intern. Med. 2013;173:1913-4.

47. Grumbach $\mathbf{K}$, Bodenheimer $\mathbf{T}$. Can health care teams improve primary care practice? JAMA. 2004;291:1246-51.

48. Grumbach $\mathbf{K}$, Bodenheimer T. A primary care home for Americans. JAMA. 2002;288:889-93.

49. Ghorob A, Bodengeimer T. Sharing the care to improve access to primary care. N. Engl. J. Med. 2012;366:1955-7.

50. Bodenheimer T. Transforming care. N. Engl. J. Med. 2008;359:2086-9.

51. Bodenheimer T, Willard-Grace R, Ghorob A. Expanding the roles of medical assistants. Who does what in primary care? JAMA Intern. Med. 2014;174:1025-6.

52. Barzansky B, Etzel SI. Medical schools in the United States 2011-2012. JAMA Intern. Med. 2012;308:2257-63.

53. Pugno PA, Schmittling GT, Fetter GT, Kahn NB. Results of the 2005 national resident matching program: family medicine. Fam. Med. 2005;37:555-64.

54. Schwartz MD. The US, primary care workforce and graduate medical education policy. JAMA. 2012;308:2252-3.

55. Newton DA, Grayson MS. Trends in career choice by US medical school graduates. JAMA. 2003;290:1179-82. 
56. Colquitt WL, Zeh MC, Killian CD, Cultice JM. Effect of dept on U.S. medical school graduates' preference for family medicine, general internal medicine, and general pediatrics. Acad. Med. 1996;71:399-411.

57. Rosenblatt RA, Andrilla HA. The impact of U.S. medical students' debt on their choice of primary care careers: an analysis of data from the 2002 medical school graduation questionnaire. Acad. Med. 2005;80:815-9.

58. Kassler WJ, Wartman SA, Silliman RA. Why medical students choose primary care careers. Acad. Med. 1991;66:41-3.

59. Scott I, Gowans M, Wright B, Brenneis F, Banner S, Boone $J$. Determinants of choosing a career in family medicine. Can. Med. Assoc. J. 2011;183:E1-8.

60. Schwartz MD, Linzer M, Babbott D, Divine GW, Broadhead WE. For the society of general internal medicine task force on career choice in internal medicine. The impact of an ambultory rotation on medical student interest in internal medicine. J. Gen. Intern. Med. 1995;10:542-9.

61. Phillips JP, Weismantel DP, Gold KJ, Schwenk TL. Medical student dept and primary care selection intentions. Fam. Med. 2010;42:616-22.

62. Youngclaus JA, Koehler PA, Kotlikoff $\mathbf{L}$, Weicha JM. Can medical students afford to choose primary care? an economic analysis of physician education debt repayment. Acad. Med. 2013;88:16-25.

63. Senf JH, Campos-Outcalt D, Kutob R. Factors related to the choice of family medicine: a reassessment and literature review. J. Am. Board Fam. Pract. 2003;16:502-12.

64. Ende J. Feedback in clinical medical education. JAMA. 1983;520:777-81.

65. der Jochemsen-van Leeuw HGARR. The attributes of the clinical trainer as a role model: a systematic review. Acad. Med. 2013;88:26-34.

66. Washington AE, Coye MJ, Feinberg DT. Academic health centers and the evolution of the health care system. JAMA. 2013;310:1929-30.

67. Grumbach K, Lucey CR, Johnston SC. Transforming from centers of learning to learning health systems. The challenge for academic health centers. JAMA. 2014;311:1109-10.
68. Bitton A, Ellner A, Pabo E, et al. The Harvard Medical School Academic innovations collaborative: transforming primary care practice and education. Acad. Med. 2014;89:1239-44.

69. Pefkoff GT. General internal medicine, family practice or something better? N. Engl. J. Med. 1978;299:654-7.

70. Friedman RH. Family practice and general internal medicine: what kind of cooperation makes sense? JAMA. 1986;255:2644-6.

71. Saver BG. Attracting students to primary care. N. Engl. J. Med. 2005;352:93.

72. Sheline B, Tran AN, Jackson J, Peyser B, Rogers S, Engle D. The primary care leadership track at the Duke University School of Medicine: creating change agents to improve population health. Acad. Med. 2014;89:1370-4.

73. Abelson R. The new faces of health care. The Cleveland Clinic grapples with change. The New York Times. 2015 3/18/15;Sect. 2.

74. Choi PA, Xu S, Ayanian JZ. Primary care careers among recent graduates of research-intensive private and public medical schools. J. Gen. Intern. Med. 2013;28:787-92

75. Meurer LN. Influence of medical school curriculum on primary care specialty choice: analysis and synthesis of the literature. Acad. Med. 1995;70:388-97.

76. Campos-Outcalt D, Senf $\mathbf{J}$. A longitudinal, national study of the effect of implementing a required third-year family practice clerkship or a department of family medicinei on the selection of family medicine by medical students. Acad. Med. 1999;74:1016-20.

77. Duerson MC, Crandall LA, Dwyer JW. Impact of a required family medicine clerkship on medical students' attitudes about primary care. Acad. Med. 1989;64:546-8.

78. Fincher R-ME. Attracting students to primary care. N. Engl. J. Med. 2005;352:95.

79. Gourevitch MN. Population health and the American medical center: the time is right. Acad. Med. 2014;89:544-9. 